\title{
Foreword I
}

\section{Christophe Bernasconi}

We live in a world of private international law. Increases in cross-border movement, transnational commerce and the rise of technology have all highlighted the importance of the discipline and led to an increased awareness of its relevance. As these developments occur, and individuals are faced with challenges that operate across legal systems, the work of the $\mathrm{HCCH}$ is more relevant than ever.

The collection of essays found in this compilation reflects the diversity and scale of the $\mathrm{HCCH}$. It provides a comprehensive overview of the Organisation, its journey across the past century, and the Conventions and other instruments that it has produced. The authors are academics, judicial officers, and practitioners from across the world, all of whom have shown great interest in the $\mathrm{HCCH}$ and have directly or indirectly contributed to the development of its normative work. I am grateful for their thought-provoking contributions. These experts are merely a sample (albeit an impressive one) of the many great minds who have engaged with the HCCH across its tenure, beginning with Tobias Asser in 1893.

While I defer all substantive matters to the rich content you will find in the following pages, there are a number of key themes I wish to highlight, reflecting the history and personality of the $\mathrm{HCCH}$. It tells a story of resilience and adaptability as it provides a multilateral platform focused on 'connecting, protecting, co-operating'.

The HCCH is dynamic. It has changed its operating methods to accommodate international developments. Over time, we have strengthened good governance, including restructuring internal bodies and their rules of operation. The key vehicle for setting the Organisation's work programme and its policy is now the Member-driven Council on General Affairs and Policy, which meets every year. The $\mathrm{HCCH}$ also swiftly managed to amend its Statute enabling Regional Economic Integration Organisations to become Members of the Organisation; as a result, in 2007, the European Union became a Member of the HCCH (in addition to its own Member States).

The HCCH is resilient. The history behind the 2005 Choice of Court Convention, 2019 Judgments Convention and the ongoing jurisdiction project show both the challenges of negotiating international agreements, and the rewards. What began as a project with a wide scope was eventually narrowed and broken into separate instruments. To continue to produce meaningful, practical and consensus-based outcomes while facing renewed challenges in developing its normative work has necessitated perseverance at each obstacle.

The $\mathrm{HCCH}$ is adaptable. Across this compilation, there are stories of communication and innovation in an effort to embrace advancements in law and technology. Networks have been created, such as the International Hague Network of Judges, in response to jurisdictions having no existing formal mechanism to communicate. This is in addition to regular post-Convention activities such as Special Commissions on the Practical Operation of Conventions, a format which was first established in 1977 to consider the 1965 Service Convention. These fora unique to the $\mathrm{HCCH}$ - hold crucial importance to the ongoing success of its instruments by contributing to uniform interpretation and enabling Conventions to operate in a changing environment. The publication of Guides to Good Practice and Practical Handbooks enable different jurisdictions to adopt common practices while accounting for domestic limitations. Finally, the ongoing role of Central and Competent Authorities, a mechanism central to 
a number of Conventions, sees individuals numbering into the thousands become part of the work of the $\mathrm{HCCH}$ every day.

The HCCH is effective. It has shown skill in its nuanced drafting processes, both with bilingual drafting and in conceptualising difficult legal concepts into neutral language to ensure Conventions are able to have universal application. HCCH Conventions have real-life practical effect for individuals. The 1961 Apostille Convention assists millions of people around the world every year, and continues to attract signatories. Its Contracting Parties now well exceed 100, a milestone also passed by the 1980 Child Abduction and 1993 Adoption Conventions. More broadly, there are over 930 instances of an $\mathrm{HCCH}$ Convention being brought into force by a Contracting Party, yet more than 28,500 agreements would be required to replicate this network at the bilateral level. The benefits of multilateralism thus speak for themselves, saving resources at an international, consular, and individual level. It is not unreasonable to expect this to span further as we progress through the twenty-first century. Finally, new systems have been created in response to new technologies. Conventions that were drafted decades ago, in a wholly paper-based world, have employed new online methods, such as the e-APP (the electronic Apostille Programme), iSupport (an electronic case management and secure communication system for the cross-border recovery of maintenance obligations) and INCADAT (the International Child Abduction Database).

Of course, we continue to face challenges which are inherent to an international body. Traditional understandings of private international law are being challenged by new technologies, such as distributed ledger technology, which is decentralised and delocalised. Unique challenges triggered by catastrophe - such as natural disasters or global pandemics - have implications on both everyday life and the ability to access legal and administrative processes. In these circumstances, both the normative and non-normative work of the HCCH has proven helpful in assisting persons at risk and in need. The $\mathrm{HCCH}$ is on the front foot, and will continue to respond to challenges, providing a forum for the future.

As an organisation, we continue to go from strength to strength. Over the last decade - at the time of writing - the $\mathrm{HCCH}$ witnessed 16 new Member States and over 250 instances in which a Contracting Party joined an $\mathrm{HCCH}$ Convention. We have celebrated milestones including the 125th Anniversary of the HCCH in 2018, and the conclusion of the 2019 Judgments Convention, a potential gamechanger for private international law. In line with broader strategic goals, we now have two Regional Offices: the Regional Office for Latin America and the Caribbean, opened in 2005, and the Regional Office for Asia and the Pacific, opened in 2012. These are in addition to many more meetings, publications, workshops and anniversaries, which are far too many to mention in writing.

Our work encompasses local and national implementation, civil and common law systems, and individuals that come from socially, ethnically, and economically diverse backgrounds. We continue to balance priorities and remain proactive, creating ambitious goals, acknowledging shortfalls and building to be better.

I would like to extend my thanks to the authors for their time and expertise, and the editors at Edward Elgar Publishing for their assistance. I would also like to thank Thomas John, my former Attaché at the $\mathrm{HCCH}$, for his organisation and commitment to this project which have been invaluable to its completion.

The HCCH seeks to better the lives of individuals in a globalised world, a goal that remains more vital today than ever. And while there is still a long way to go to establish the HCCH as a truly global and fully inclusive organisation, in this piece of work, you will find the story of 
what it has achieved in the past, and how it will continue to do so in the future. This companion will no doubt help increase the visibility of the work of the $\mathrm{HCCH}$, and provide a useful resource about the Organisation and its role in the future development of private international law.

Christophe Bernasconi

Secretary General



